Bianca Suárez-Puerta*

\title{
Aprendizaje y enseñanza del diseño de experiencias centradas en el usuario ${ }^{1}$
}

\author{
Cómo citar:
}

Suárez, B (2019). Aprendizaje y enseñanza del diseño de experiencias centradas en el usuario. Designia 6(2), 149-157.

\author{
*Investigadora asociada en Innovación, Comunicación y \\ Cultura Universidad Nacional de Colombia con Doctorado \\ en Semiótica, Maestría en Antropología, Pregrado en Diseño. \\ Tiene experiencia en investigación de carácter cualitativo, \\ etnografía y análisis crítico del discurso. \\ e-mail: blsuarezp@unal.edu.co \\ ORCID: 0000-0003-4294-8062 \\ ${ }^{1} \mathrm{El}$ presente artículo se construye como resultado de las \\ actividades realizadas en el año 2016 por los integrantes de \\ la línea de investigación en transmedia y nuevas tecnologías \\ del grupo "Reflexiones en torno a la producción cultural". \\ Este grupo es clasificación A ante Colciencias y trabaja \\ especialmente conociendo sobre la economía y los negocios de \\ productos e industrias culturales.
}

\section{Palabras clave:}

Diseño de experiencias, diseño centrado en el usuario, semiótica, semiósfera, cine.

\section{Key words:}

Sesign of experiences, user centered design, semiotics, semiosphere, cinema.

Recibido: 12/06/2018 Aceptado: 17/10/2018

\section{Resumen:}

Diseñar experiencias (UX) innovadoras puede permitirle a los usuarios abrir nuevas dimensiones a las vivencias cotidianas, e ir más allá de las experiencias familiares basadas en diseños de pantalla. Si bien, la mayoría de los métodos para aumentar los conocimientos básicos de un buen diseño de UX todavía tienen sentido en pantallas bidimensionales, los métodos de aplicación de estos principios heurísticos cambian en el nuevo paradigma de las experiencias de realidad virtual y realidad aumentada. 
De esta manera, para cada experiencia digital, el diseñador debe iniciar con una idea para mostrar un conocimiento y luego deberá ampliarla a nuevas superficies y soportes. Cada UX requiere crear un viaje para el usuario (UCD) dentro de la idea. El diseñador decidirá qué debe automatizarse y qué debe controlar el usuario. Para comprender mejor, en el presente artículo se analizará el diseño de la experiencia cinematográfica en una sala de cine que presenta una plataforma única donde el diseñador debe pensar más allá de la interfaz. En este medio, la narración de historia es muy importante y no debe ignorarse. Como docentes de diseño es necesario conocer las posibilidades del medio para crear un entorno inmersivo en lugar de solo una interfaz. Para este aprendizaje es necesario también el conocimiento de la psicología, la arquitectura, el diseño de sonido, el diseño de iluminación y la física. En la actualidad, estos diseños de experiencias se esfuerzan por acercarse a las vivencias de la vida real; pero con el tiempo, el contenido y el uso creativo del contenido evolucionarán hacia ofrecer una nueva realidad.

De acuerdo con la experiencia descrita, la reflexión implica la realidad de la disciplina más allá del uso de la tecnología, en este caso a partir de la representación digital del objeto de diseño de diseño, su función comunicativa y vinculación con el contexto.

\section{Abstract:}

Designing innovative experiences (UX) can allow users to open new dimensions to everyday experiences, and go beyond familiar experiences based on screen designs. Although, most of the methods to increase the basic knowledge of a good UX design still make sense on two-dimensional screens, the application methods of these heuristic principles change in the new paradigm of virtual reality and augmented reality experiences. In this way, for each digital experience, the designer must start with an idea to show knowledge and then expand it to new surfaces and supports. Each UX requires creating a trip for the user (UCD) within the idea. The designer will decide what should be automated and what the user should control. To better understand, in this paper we will analyze the design of the cinematic experience in a movie theater that presents a unique platform where the designer must think beyond the interface. In this medium, the telling of the story is very important and should not be ignored. As design teachers we must know the possibilities of the medium to create an immersive environment instead of just an interface. For this learning is also necessary knowledge about psychology, architecture, sound design, lighting design and physics. Currently, these designs of experiences strive to get closer to the real life experiences; but over time, the content and creative use of the content will evolve to offer a new reality. 


\section{Introducción}

El diseño no siempre es un proceso intuitivo y, en ocasiones, deja al usuario del frustrado sobre cómo debe usar lo que el diseño propone. ¿Cuántas veces nos ha pasado que no sabemos cómo activar alguna función de nuestro nuevo smart tv y seguimos usándolo como un televisor normal? ¿Cómo podemos diseñar sistemas que se adapten a los códigos que ya sabemos utilizar?.

El papel de la estética en cualquier producto cultural, visual o audiovisual, multimedia, así como en su diseño se refiere a aquellas cosas atractivas que hacen que la gente que usa aquellos objetos se sienta bien. La estética a su vez proporciona una manera de pensar creativa, ya que está relacionada con la ética propia de un contexto. Pero, ¿Cómo se hace algo más fácil de usar, además de hacernos sentir bien? ¿Cómo logra un objeto activar la creatividad de nuestro pensamiento? La solución siempre debe ser simple, por lo que para las personas es más fácil encontrar soluciones a los problemas que encuentran. Los objetos deben apoyar a esta solución en la vida cotidiana.
En el mundo actual de cine 4D, productos digitales, notificaciones personalizadas, impresión 3D, interfaces de realidad aumentada y respuestas automáticas, se hace la misma operación de la búsqueda por la simplicidad. El diseño de experiencias busca esto mismo, con soluciones alternativas que motiven las emociones y el aparato sensorio-motor en sus tres niveles de procesamiento: el visceral, el conductual y el reflexivo. En su libro Emotional Design: Why We Love (or Hate) Everyday Things, Don Norman (2015) expone que las emociones son inseparables de cómo pensamos, elegimos y actuamos los humanos. Para concluir esto, aplica los principios de la psicología humana a la invención y el diseño de nuevas tecnologías y productos. El buen diseño exige que el usuario tenga prioridad sobre la estética de un diseño, si algo, desde los interruptores de luz hasta los aviones, funcionan como lo necesita el usuario.

A partir de las conclusiones del doctor Norman, el procesamiento visceral es el procesamiento más rápido ya que hace que los juicios de lo que es bueno o malo, seguro o peligroso, enviando señales apropiadas a los músculos, es decir al sistema de motor, 
y de esta manera alerta al resto del cerebro. Este es el comienzo del procesamiento afectivo. Estos procesos son biológicamente determinados y pueden ser inhibidos. El nivel de comportamiento se refiere a la conducta humana ya que las acciones del sujeto pueden ser mejorados o inhibidas, este es el nivel en el pensamiento reflexivo ya que no tiene acceso directo, ya sea a la entrada sensorial o para el control de la conducta; en su lugar, vigila, reflexiona sobre, y trata de empujar el nivel de comportamiento, ahora motivado por cada vez más estímulos.

Por su parte, el Diseño Centrado en el Usuario (UCD) es un término amplio para describir los procesos donde los usuarios finales influyen en la forma del diseño. Es a la vez una filosofía amplia que incluye una variedad de métodos en donde se involucra a los usuarios para influir sobre el concepto de diseño de una manera u otra teniéndolos en cuenta en momentos específicos durante el proceso de diseño. Por ejemplo, algunos tipos de UCD utilizan métodos etnográficos para conocer las necesidades de los usuarios acerca de sus maneras de usar un diseño. Así, estas metodologías de evaluaciones centrados en el usuario se llevan a cabo mediante la identificación de los usuarios representativos, los procesamientos sensoriomotores dentro de las tareas de representación, y el desarrollo de un procedimiento para la captura de los problemas que los usuarios tienen en el intento de aplicar o cumplir una acción o un desarrollo en particular en el cumplimiento de estas tareas.
Durante la aplicación de la metodología del ciclo de desarrollo de diseño de experiencias, se realizan dos tipos de evaluaciones: las evaluaciones formativas se utilizan para obtener información para el diseño inicial, mientras que las evaluaciones de usabilidad documentan la efectividad, eficiencia y satisfacción de los usuarios finales de un producto ya en el ciclo de desarrollo.

El diseño de experiencias se caracteriza por ofrecer procesos mediatizados visuales, físicos, sensoriales o en productos industriales para que el usuario pueda dar un testimonio determinado. Estas imágenes, sonidos, olores, texturas u objetos le permiten al usuario no solo sentir, sino también participar, tomar un papel y ser frente a un concepto encapsulado. Este tipo de diseño sensorial, también se relaciona con el diseño de la información, el diseño de interfaces, diseño de instalaciones y con formas artísticas como los site specific y las instalaciones interactivas.

El diseño de experiencias centrado en el usuario, desde una perspectiva cinematográfica, se caracteriza entonces por asumir que todo el proceso de diseño de personajes debe estar conducido hacia hacer que el visitante a la sala de cine se identifique con los personajes. También conduce la historia hacia satisfacer las aspiraciones, proyecciones y llenar una parte de la existencia de los usuarios participantes. Las características y objetivos de los personajes se deben centrar en satisfacer a los usuarios de una manera práctica informando directamente qué se obtendrá de su interacción o identificación con la experiencia de la película. el diseño de información debe contribuir a comprender rápidamente lo que el usuario requiera. Estos diseños de experiencia 
se reconocen como procesos cognitivos donde la información contenida en la obra, en la experiencia o en la interfaz interactúa con el sujeto espectador. De esta manera, la experiencia vincula al sujeto y los conceptos que contiene, los aspectos sensoriales del objeto o de la experiencia son un medio para la recepción y la reflexión. La experiencia, en tanto medio, permite comprender el concepto contenido en la película. La comprensión es el efecto de esta comunicación.

\section{¿Qué es diseño de experiencias en el contexto cinematográfico?}

Desde sus inicios, las películas han sido el lugar propicio para probar tecnologías mucho antes de su comercialización, como por ejemplo en teléfonos para realizar video - llamadas, sensores de identidad por medio de la retina, sistemas de realidad virtual. Por su atractivo, en muchos casos estas innovaciones son adoptadas y comercializadas, tal vez debido a su impacto cinematográfico.

Los medios populares han servido como simuladores informales para las nuevas tecnologías, en las que interactúa el usuario con la máquina, es decir con bases de datos, infografías, botones, aplicaciones, de esta manera el usuario interactúa en una función comunicativa. Es así como por medio del cine se prueban una amplia cantidad de interfaces que ofrecen evidencias para la evaluación heurística, análisis etnográfico, análisis de mercado, crítica de personajes y escenarios de uso, y los nuevos enfoques para el diseño conceptual, visual y finalmente para el diseño de identidad.

Como fue mencionado antes, el diseño de experiencias centradas en el usuario (UCD) es una metodología que posibilita una determinada vivencia. Aquello que puede ser denominado como un procesamiento afectivo que se constituye como una vivencia, o el recuerdo de algo. Esta vivencia alude a cierta experiencia dotada de mayor impacto, sentido y conciencia, por lo que almacenamos recuerdos de nuestras vivencias y no meras experiencias. Este procesamiento afectivo es entendido como una actividad mental que tiene un usuario receptor ante un sistema de información que puede ser puramente audiovisual, como en el cine, pero por un diseño de experiencia exitoso este procesamiento del pensamiento se convierte en una experiencia sensorial ofreciéndose en olores o texturas, en movimientos o también puede motivar un movimiento a partir de un estímulo.

Por su parte el lenguaje cinematográfico, que no tiene una definición única y clara sobre la relación entre la imagen y el sonido en un tiempo, recurre a la creación de historias, personajes, generando patrones sensoriales y motores. Estos patrones o indicaciones que se repiten en el texto cinematográfico son utilizados como recursos para el cine convencional que permite regular actos y efectos de sentido de acuerdo con los miembros de un grupo. Este proceso institucionalizado por la industria cinematográfica no depende solamente del lenguaje del sonido, el montaje y los géneros; también depende del estilo de un director, o empresas productoras de una película. Estas instituciones guardan una macro-estructuralidad que alberga diferentes intereses, y son también influidas por escuelas de estudios cinematográficos, incluso también la institucionalidad de la historia, la literatura y el teatro de un país. 
Entonces, en el momento de estructurar un guión y darle vida a un personaje que le ofrezca al espectador una experiencia, se debe partir de estructuras sólidas, convencionales, fácilmente reconocibles, para que sea posible diseñar este efecto de comprensión que pueda ser medido social y culturalmente. George Herbert Mead, raíz sociológica de la acción comunicativa y padre fundador del interaccionismo simbólico, en su libro La Naturaleza de la Experiencia Estética (1926), nos muestra cómo analizar estos gestos del usuario comprendiendo o interactuando con un guión como comunicación, en tanto entendimiento del mundo social a través del juego de interpretar. Por ejemplo, los niños al ver alguna película de algún superhéroe a medida que van jugando adoptan las formas verbales del personaje, su papel o rol.

\section{La enunciación en el cine convencional}

La función simbólica en el cine, así como en otras materialidades estéticas, depende de una convencionalidad arbitraria, donde la forma significante está dada por el uso y el contexto de enunciación, estableciendo un signo como portador de sentido arbitrariamente. Aunque arbitrarios, en particular, aquellos elementos que contribuyen a producir experiencias superiores son conocidos, conocibles, reproducibles y de alguna manera se vuelven estáticos para la cultura así como elementos arbitrarios, reconocibles, convencionales y estáticos de héroes de ficción, como el brazo y el pecho brillante del héroe de la película Ironman dirigida por Jon Favreau en 2008-.

El modelo dinámico del sistema de significación propuesto por Iuri Lotman (1998, pág. 43) plantea una solución frente a este problema de lo estático y lo dinámico en los sistemas semióticos. Al establecer este carácter dinámico al concepto de cultura, permite pensar las relaciones sistémicas que rigen las relaciones, e interacciones, adecuándose a condiciones cambiantes, que presentan la mayoría de organizaciones productivas, como las biósferas.

La semiósfera, análogo al concepto de biósfera, corresponde con un continuum semiótico ocupado por formas semióticas de diversos tipos y que se hallan en diversos niveles de organización. Para este continuum es importante todo el sistema de significación no solamente el espacio dentro, sino también el espacio fuera de la semiosfera (Lotman, 1998, pág. 22-24). Por este motivo, la frontera que delimita a la semiósfera permite tomar en cuenta materiales extra-sistémicos para entender porque los elementos irregulares que la integran funcionan de tal manera, así como también expulsar elementos para separarlos y así tomar conciencia de su sentido semiótico-cultural. (Lotman, 1998 pág. 28). 
Esta noción de semiósfera se refiere entonces al entorno semiótico en que ocurre la comunicación, derivado de símbolos, códigos y leyes que mantienen un gran atractivo interdisciplinario. Esta semiósfera tiende a reemplazar las categorías binarias sobrantes de estructuralismo, aunque a veces logran mantenerse en el deconstructivismo, ya que parte del sistema, es tenido en cuenta como una fracción que aporta al conocimiento de todo el sistema semiótico, ya que hace hincapié en cambiar los límites y las jerarquías, las permutaciones entre el centro y la periferia, mediaciones y traducciones, las relaciones isomórficas entre eventos en el nivel macro y micro, y persigue alguna unidad en la diversidad.

Por tal motivo, la metáfora biológica de la semiósfera no sirve para hallar la esencia del discurso, sino para regresarle el sentido continuo de la vida a las partes en diálogo. Este sentido persiste a partir de juegos ininterrumpidos, intercambios metabólicos incesantes en los discursos que tienen sentido cuando son arrojados al mundo.

La relación dinámica con el contexto cinematográfico opera bajo un conjunto de prácticas normativas propio de instituciones culturales. Entonces, al conocer los vehículos sígnicos de este dinamismo entre los elementos arbitrarios y estáticos del cine, y los elementos dinámicos de la experiencia que activa una respuesta sensorio-motriz en el usuario y en constante evolución según el contexto de recepción, se puede proveer algún tipo de resolución sobre la configuración del diseño de experiencias en su totalidad como una biósfera.

Esta significación de la totalidad se puede dar, ya sea a través de estimar el significado de la película, la historia a la que se refiere o el contexto de enunciación, o a partir de deconstruir los estímulos y las respuestas para que la actividad de la experiencia de la película que se haga disfrutable y satisfactoria. En esta comprensión se habilita que este conocimiento pueda ser reproducible fuera del contexto de la sala de cine.

Entonces, esta dinámica de significación al interior de lo estático e icónico de lo cinematográfico y al exterior propio del contexto cultural permitió encontrar una discusión plausible sobre los actos de significado de personas que quieren identificarse con una película específica, y así, aportar al aprendizaje y a la enseñanza del diseño de experiencias. Esta dinámica propia de la semiósfera cinematográfica cumple un intercambio entre el proceso de significación de una forma argumentativa, otra de naturaleza retórica y de persuasión principalmente estética, y finalmente una forma de identificación y aspiración relacionada con las necesidades del usuario.

Estas tres formas de significación en diálogo buscan que la experiencia tenga una duración o una sostenibilidad en el tiempo. Esta condición de duración se refiere al nivel de inmersión que puede producir una experiencia, gracias a sus características envolventes. La argumentación, la persuasión y la identificación ofrecen un significado personal y una vinculación emocional del usuario con la película. 
Los sujetos de la enunciación, incluyendo a las instituciones que los forman, quieren vincular a los usuarios de la película formando una cadena de unidades sintomáticas o culturales que alude a la organización social y a la construcción de modelos. Estos modelos logran engañar la mente, enmascarando la realidad con impresionantes formas realistas y verosímiles.

\section{Conclusiones}

El diseño de experiencias cinematográficas convencionalmente se entiende como la serie de procesos de programación para relacionar arbitrariamente una imagen, un objeto a un actor dentro de la trama de la película. Esta capacidad del diseño para asociar valores a la imagen de algo, se construye en un proceso de codificación, persuasión y retórica visual para proyectar la imagen de algo como algo reconocible. Este proceso cognitivo de proyectar cómo se relaciona una imagen con los valores y emociones, parte de cargar la proyección con una experiencia de diferencia, que el público puede recordar y reproducir -tal como hacer el gesto de la mano de Ironman afuera de la sala de cine-.

El diseño de experiencias centradas en el usuario es una perspectiva altamente interdisciplinaria, así como también transdisciplinaria, que considera varios aspectos del mercado y la marca. En el caso específico de la industria cinematográfica incluye las disciplinas de diseño de producto, merchandising, dirección de arte, así como también el ambiente de los puntos publicitarios, los videojuegos que complementan las películas, hasta los juegos de roll derivados. También será interesante estudiar en un futuro cómo este diseño de experiencias modela el estilo de vida, e imaginarios sociales de muchos que se vuelven aficionados a una película.
El diseño de experiencia solo debe poner en relación los signos icónicos arbitrarios y estáticos en la cultura, para que el público los identifique con una identidad diferente y dinámica, y los reconozca en esa nueva imagen presentada en la película. Los valores y emociones de los que está cargado, como por ejemplo la mano de Ironman. Entonces, la información sensorial y cognitiva activa gatillos que apuntan a los sentidos y al intelecto, el cuerpo es empujado a reproducir el gesto y el mensaje codificado que viaja en la mano robótica y luminosa del superhéroe, es emitido no solamente por el guionista, el director de la película y el diseñador de indumentaria, en una cadena sintagmática, sino que la cadena continúa en el fabricante de merchandising, las programadoras hasta llegar al usuario que decide usar ese mensaje codificado apropiándolo.

En este proceso de la construcción emotiva de una identidad, también se alude al diseño persuasivo que aborda todo lo relacionado con la articulación de discursos visuales afectivos propios de la publicidad y el marketing. El público reconoce en la imagen diseñada algo que aspira obtener, comprar, recordar o ser; es seducido por las sensaciones evocadas por la identidad diseñada. La semiósfera entonces propicia el surgimiento de nuevas informaciones sobre la misma película, no como textos aislados, sino como fragmentos con mecanismos de reconstrucción de todo el sistema. El mensaje encapsulado en una mano de Ironman está configurado en varios niveles de complejidad, asumiendo los disímiles criterios de equivalencia con cuidado para que el mensaje, en este caso de una mano super poderosa por encima de un cuerpo natural humano, pueda ser entendido 
por públicos diversos. ¿Cuántos de los mensajes producidos en películas taquilleras, permanecen en la memoria de las personas hasta motivarlos a construir su propia identidad a partir de ellas?

El diseño de experiencias habla del avance de la economía de mercado, en el ámbito mundial que supone la transformación del concepto de individuo a una experiencia y ejercicio de la ciudadanía. En este avance el individuo pasa de ser un simple cliente a hacer parte de una comunidad que escucha, participa, desea, aspira, proyecta y finalmente es. El usuario existe en su contexto con capacidad de agenciamiento. El bienestar de los bienes y servicios ofrecidos por el mercado debe dirigirse hacia grupos sociales específicos, con una capacidad económica. También es importante tener en cuenta cómo estos usuarios hacen parte de mercados emergentes y públicos juveniles por lo cual quedan excluidos de la evolución del mercado aquellos colectivos sociales sin potencial de consumo.

La dinámica al interior de la semiósfera del diseño de la experiencia de usuarios, particularmente de experiencias cinematográficas, tiene la función de generar un diálogo que permita una compleja traducción de la información que le entrega la película y sus productores, en un idioma que pueda entender tanto la amplia audiencia de una película taquillera, pero que puede finalizar en un resultado sensorial que afecta la experiencia de sí. Esta experiencia transforma el ser de algunos sujetos que desean convertirse en el personaje de una película de tal manera que le sean útiles para alcanzar un entendimiento, simbolizando su nuevo rol social.

\section{REFERENCIAS BIBLIOGRÁFICAS}

Lotman, I. (1998). La semiosfera II: semiótica de la cultura, del texto, de la conducta y del espacio. Madrid: Frónesis, Cátedra, Universitat de València.

Mead, G. H. (1926). La Naturaleza de la Experiencia Estética. Barcelona: Atenea Digital. Recuperado de: http://atheneadigital.net/article/view/n0-mead/6-html-es

Mead, G. H. (1934). Espíritu, Persona y Sociedad. Persona y Sociedad desde el punto de vista del conductismo social. Barcelona: Paidós.

Norman, D. (2005). Emotional Design: Why We Love (or Hate) Everyday Things. New York: Basic Books. 